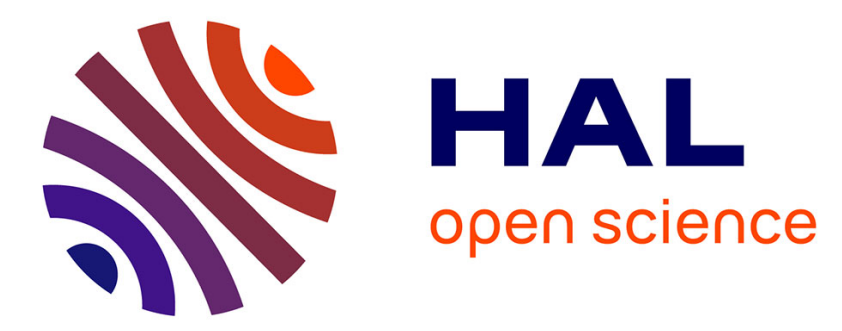

\title{
3-D Multi-Nodal Thermal Modelling for Fault-Tolerant Machine
}

Safouene Ouenzerfi, Hussein Zahr, Mohamed Trabelsi, Riadh Boubaker, Eric Semail, Souad Harmand

\section{- To cite this version:}

Safouene Ouenzerfi, Hussein Zahr, Mohamed Trabelsi, Riadh Boubaker, Eric Semail, et al.. 3-D MultiNodal Thermal Modelling for Fault-Tolerant Machine. 2019 IEEE International Conference on Industrial Technology (ICIT), 2019, melbourne, Australia. pp.1551-1556, 10.1109/ICIT.2019.8755164 . hal-02498285

\section{HAL Id: hal-02498285 \\ https://hal.science/hal-02498285}

Submitted on 4 Mar 2020

HAL is a multi-disciplinary open access archive for the deposit and dissemination of scientific research documents, whether they are published or not. The documents may come from teaching and research institutions in France or abroad, or from public or private research centers.
L'archive ouverte pluridisciplinaire HAL, est destinée au dépôt et à la diffusion de documents scientifiques de niveau recherche, publiés ou non, émanant des établissements d'enseignement et de recherche français ou étrangers, des laboratoires publics ou privés. 


\section{3-D MULTI-NODAL THERMAL MODELLING FOR FAULT-TOLERANT MACHINE}

\author{
Safouene Ouenzerfi \\ LAMIH UMR CNRS 8201, Université \\ de Valenciennes et Hainaut-Cambrésis \\ 59313, Valenciennes, France \\ ouenzerfi.safouene@gmail.com \\ Riadh Boubaker \\ LAMIH UMR CNRS 8201, Université \\ de Valenciennes et Hainaut-Cambrésis \\ 59313, Valenciennes, France \\ riadh.boubaker@gmail.com
}

\author{
Hussein Zahr \\ Univ Lille, Centrale Lille, Arts et \\ Métiers ParisTech, HEI, EA 2697 - \\ L2EP Laboratoire d'Electrotechnique et \\ d'Electronique de Puissance de Lille, \\ F-59000 Lille, France \\ Hussein.zahr@ensam.eu \\ Eric Semail \\ Univ Lille, Centrale Lille, Arts et \\ Métiers ParisTech, HEI, EA 2697 - \\ L2EP Laboratoire d'Electrotechnique et \\ d'Electronique de Puissance de Lille, \\ F-59000 Lille, France \\ Eric.Semail@ensam.eu
}

\author{
Mohamed Trabelsi \\ Univ Lille, Centrale Lille, Arts et \\ Métiers ParisTech, HEI, EA 2697 - \\ L2EP Laboratoire d'Electrotechnique et \\ d'Electronique de Puissance de Lille, \\ F-59000 Lille, France \\ Mohamed.Trabelsi@ensam.eu \\ Souad Harmand \\ LAMIH UMR CNRS 8201, Université \\ de Valenciennes et Hainaut-Cambrésis \\ 59313, Valenciennes, France \\ souad.harmand@univ-valenciennes.fr
}

\begin{abstract}
Even if intrinsically a five-phase machine can work with one opened phase, thermal constraints (temperatures in windings and Permanent Magnets) impose to decrease the mean torque in faulty operation mode. In order to elaborate optimum control which ensures safety and maximum torque, it is necessary to estimate in real-time the temperatures induced by the currents imposed in the remaining healthy windings of the machine. For a five-phase prototype, a multi-nodal thermal modelling which can take into account irregular losses and flow distribution has been developed. It is based on Electromagnetic FEM results for the losses and CFD calculation analysis. Results are presented in normal and faulty operation modes.
\end{abstract}

Keywords-Thermal nodal model, SAME code, FEM electromagnetic simulation, Integrated drive, Fault operation mode

\section{INTRODUCTION}

Electrical Integrated Drives [1]-[2], with power converter inside the machine, are attractive solutions for applications such as hybrid automotive [3]-[5]where a lot of different components must be put together in a limited volume without electromagnetic compatibility problem. But this simplicity induces, if the volume is limited, higher thermal constraints on the components for the drive and especially for the transistors. A multiphase machine which can continue to work in case of a transistor failure is then interesting. Anyway, a thermal modelling allowing temperature prediction especially in fault mode is necessary for managing the current supply and torque control as in [6][7].

In [6],[8] the prediction of five-phase motor temperatures under faulty operation has been achieved using FE Thermal analysis considering only a radial propagation of heat. In [9], a Lumped Parameter Network with 15 nodes has been developed for a Fault-Tolerant 4-phase machine considering axial and radial heat propagation but only for normal mode operation. On the other hand, electrical machine has to be characterized in order to avoid heating limits inside. Thus, several studies investigate the thermal behavior of the machine in order to ensure a satisfactory cooling [10]. Improvements for cooling inside the machine were numerically investigated [11]-[12].
In this paper, the studied machine has been developed for a low voltage $(48 \mathrm{~V})$ hybrid automotive application. For this purpose, a tooth concentrated winding has been chosen: the manufacturing of the windings is simple and the thermal couplings between the copper coils are low. Because of this intrinsic thermal robustness, it appears as a good candidate for integration. On contrary, radial but also axial propagations of the heat must be considered since the endwindings are cooled thanks to 2 fans fixed on both ends of the rotor.

This paper presents a 3D multi-nodal thermal modelling [13] for fault tolerant machine. Experimental investigations are presented as well and compared with the considered thermal model.

The paper is organized as follows: after presentation of the machine topology and the experimental test bench in section II, the thermal modelling will be described in section III. In section IV, results will be given for both healthy and faulty operation mode in order to show the effectiveness of the nodal modelling.

\section{ELECTRICAL MACHINE DESCRIPTION}

\section{A. Machine topology description}

The machine under investigation is a 20-slot/14-pole five-phase machine with 20 tooth-concentrated coils and radial buried magnets. Around each tooth is wound an electric coil (10 turns of insulated copper wire per coil). Thus, in each slot there are 20 wires.

In the rotor, the machine has 14 areas with Permanent Magnets (PM), each area creating a North or South Pole. These areas are located inside stacked ferromagnetic sheets as shown in Fig.1.a. Fourteen rods keep the rotor pack with the magnets. On the rotor are fixed, on both sides, fans in order to ensure the flow of air inside the machine as depicted in Fig.1.c. However, the connection box located at the upper side of the machine (Fig.1.a) makes less efficient the cooling in this side. The system rotor / stator is closed by aluminum frames with lateral and frontal openings, as shown in Fig.1.b and Fig.1.d respectively, in order facilitate the flow of the air. At the back of the machine, a plate of electronic components is attached. 


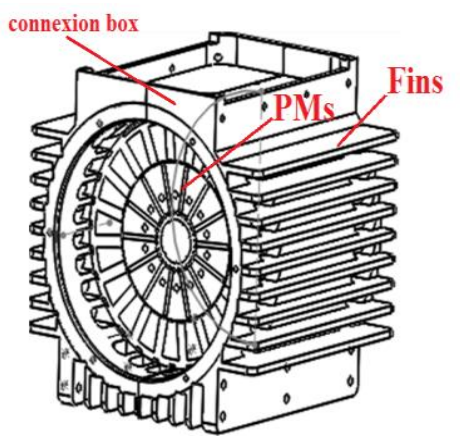

(a)

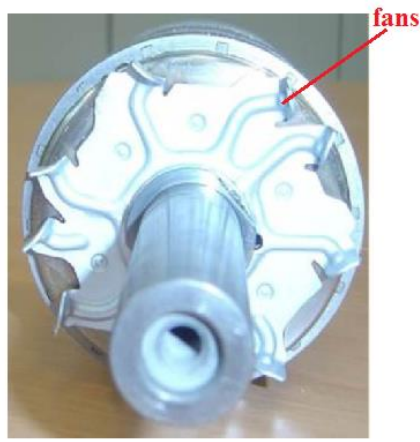

(c)

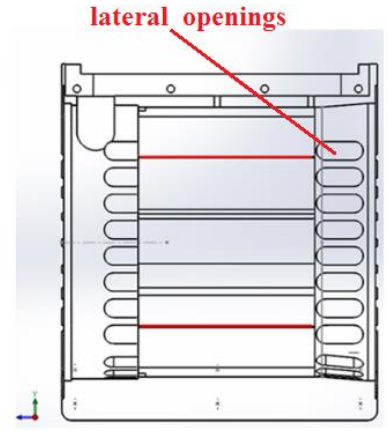

(b)

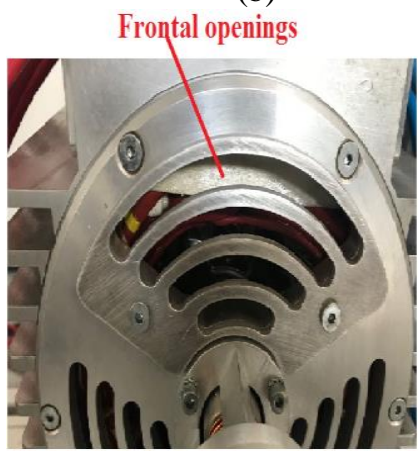

(d)

Fig.1. (a) Global view Five-phase machine topology and design. (b) Lateral view of the machine with lateral openings.(c) Rotor topology with fans. (d) front view of the machine with frontal openings.

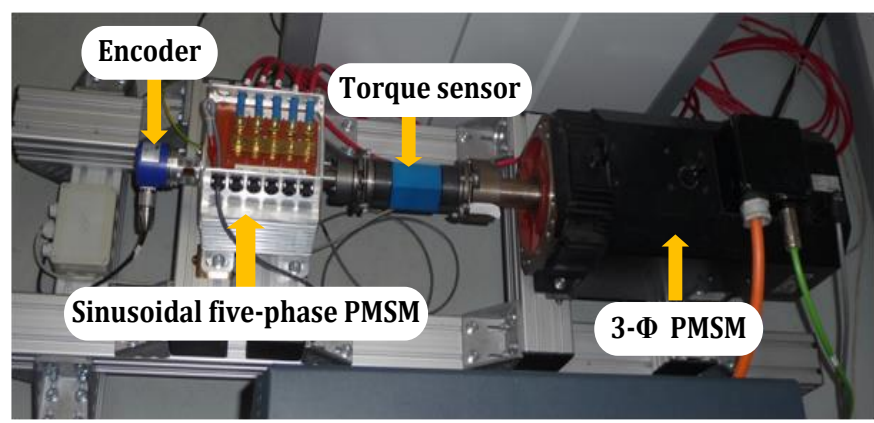

(a)

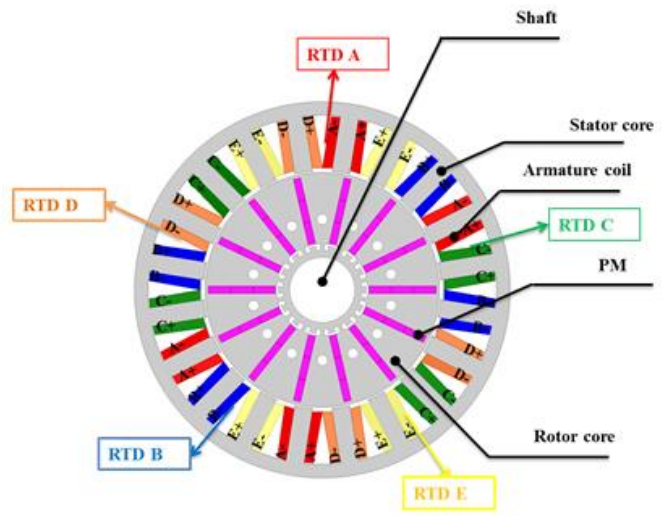

(b)

Fig.2. (a) Photo of the test bench: Overview of the power and control station. (b) Thermal detectors location.

\section{B. Experimental test bench description}

The experimental test-rig is composed of a five-phase PMSM interfaced with a digital control board based on a dSPACE DS1006 running with an execution step time of $40 \mu \mathrm{s}$. This machine, driven by a five-leg voltage source

inverter (VSI), is coupled to an industrial motion drive which is used as a mechanical emulator to generate different load profiles. A DC-bus voltage of $48 \mathrm{~V}$ is applied to the VSI.

Fig.2. depicted the experimental test-rig. In order to characterize the thermal behavior in pre-fault and post-fault operation modes, five Resistance Thermal Detector (RTD) have been inserted on the five phase motor windings, as shown in Fig.2.b. Each RTD is located within the slot in contact with the copper and it is linked to a data acquisition system that allows plotting the temperature versus time curve.

\section{Simulation TOOLS}

\section{A. Thermal nodal model}

In order to model heat transfers, several methods are possible: by Computational Fluid Dynamics (CFD), Finite Elements or nodal method. The first two methods are based on the resolution directly from partial differential equations. Unlike finite elements, CFD can only model the flow inside the machine. However, the method that seems the most effective is the nodal method. This method uses the electrical analogy and cut the machine in small isothermal volumes connected by thermal conductances.

On the other hand, nodal model is a widespread choice because it is easier to handle especially in control and real time applications. Hence, the nodal method (Lumped model) called SAME (Aerothermal Simulation of Electrical Machines) is used in order to model our thermal machine. SAME is a simulation code of the thermal rotor / stator systems and it was developed under Matlab (C) in previous years in our laboratories.

The nodal method considers the machine as a sum of small isothermal volumes interconnected by conductances whose expression depends on the nature of the transfer thermal. This simplified modeling has the main advantage of its low cost of calculation: the thermal problem is reduced to a simple matrix calculation. However, to calculate the transfer by convection, it is necessary to get closer to correlations from the literature for simplified configurations. Calibration of the model with results experimental is also most often necessary.

The SAME calculation process is divided into three main steps:

- The creation of geometry (small volumes considered isothermal). It is about cylindrical discretization along the axes $(\mathrm{r}, \Theta, \mathrm{z})$ adapted to rotating machines.

- The calculation of characteristic matrices in each mesh.

- The resolution of the system in order to determine the temperature field in the machine.

A network of thermal conductances models the heat transfers between all the volumes. These conductances have different expressions depending on the nature of the heat transfer: conductive, convective or fluidic. In steady state, three characteristic matrices are necessary to implement the system of equations: the conductances, the losses and the boundary conditions. Each mesh checks the following relation given in (1).

$$
\sum_{i \neq j} G_{i j}\left(T_{j}-T_{i}\right)=P_{i}
$$




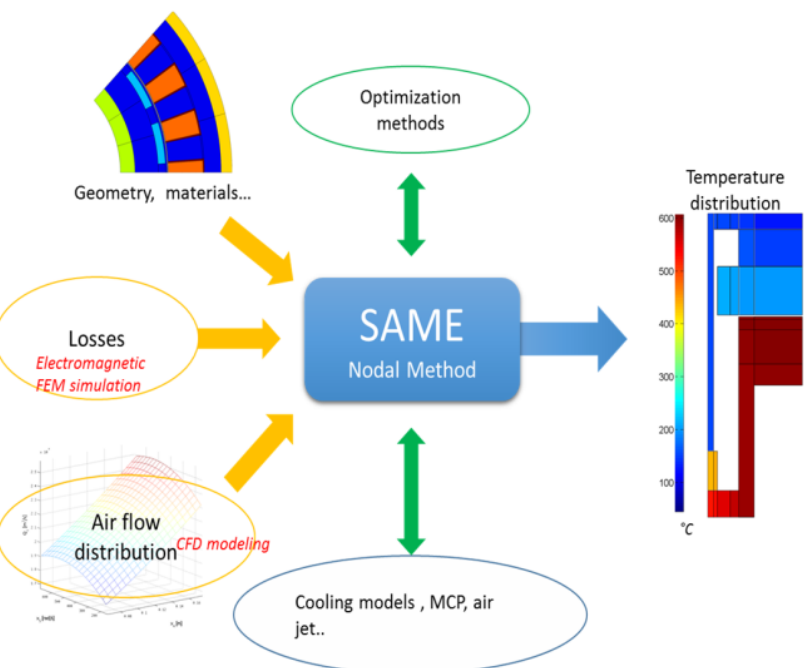

Fig.3. Schematic of the functioning of code SAME in order to determine the temperature distribution.
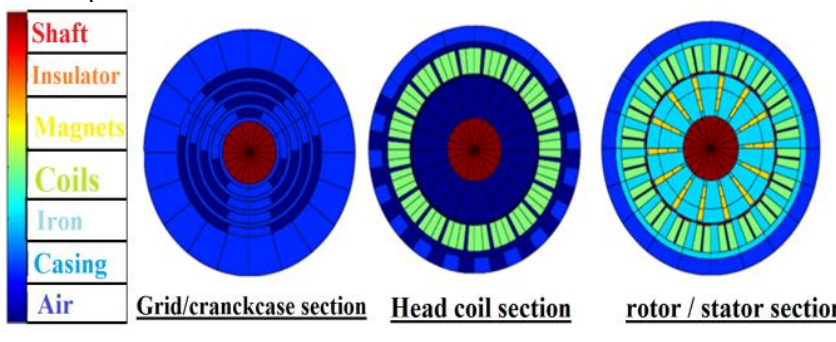

Fig.4. The meshing of the studied five-phase machine for different sections.

In order to calculate fluid and convective conductances, SAME code needs the flow distribution inside the machine. Thus, CFD calculations are achieved in order to determine the flow rate for each node (see section III.C). The heat source distribution is also necessary in order to determine the temperature distribution in the machine. They are obtained by evaluating losses in the machine using Electromagnetic FEM using the software Maxwell/ANSYS (see section III.B). Fig.3. summarizes the procedure and the required steps in order to determine the temperature distribution in the considered machine using SAME code.

For a nodal method, on contrary to more local methods that can be found in CFDs, no strict rule of division exists.

However, a finer mesh is necessary at the critical points of the machine in order to obtain the gradients of temperature or the hot spots. The mesh also depends on the digital resources that we want to allocate to the calculation: each additional mesh adds a dimension to the matrix of conductances which must be reversed at the end of computation.

When creating the division of the machine, the following rules have been applied:

- For every mesh we have only one type of material in order to avoid the calculation of equivalent conductivities.

- $\quad$ Have a finer mesh (division) in terms of heat sources and critical areas (windings, magnets ...).

- The fluid mesh must respect the mapping of the flow.

- In order to simplify the model, flows are coming out of only one or two faces of the mesh.

Once created, the geometry is used to calculate the matrices needed for the calculation. Taking into account all these constraints, the number of nodes in the studied machine is 3050(fig.4).

\section{B. FEM electromagnetic simulation and losses calculation}

Thanks to FEM software Maxwell/ANSYS, heat sources (losses) are evaluated in the coils (copper losses), the iron sheets and the permanent magnets in normal and faulty operation mode. These losses represent the heat sources for the multi-nodal model as shown in Fig.5. In Fig.6.a are given the losses density distribution for copper losses of $250 \mathrm{~W}$ and rotation speed of $750 \mathrm{rpm}$ under healthy operation mode. Since currents are identical between healthy phases, the same losses density is obtained for all the windings.

On the other hand, Fig.6.b. shows the losses density distribution in faulty mode operation where the phase $\mathrm{A}$ is opened. The same functioning conditions as in the healthy mode are considered (copper losses of $250 \mathrm{~W}$ and $750 \mathrm{rpm}$ as rotation speed). Since the currents injected in the remaining healthy phases are not identical, the losses densities are different between the windings. This irregularity of the distribution of the losses amplifies the irregularity in the temperature distribution in the machine.

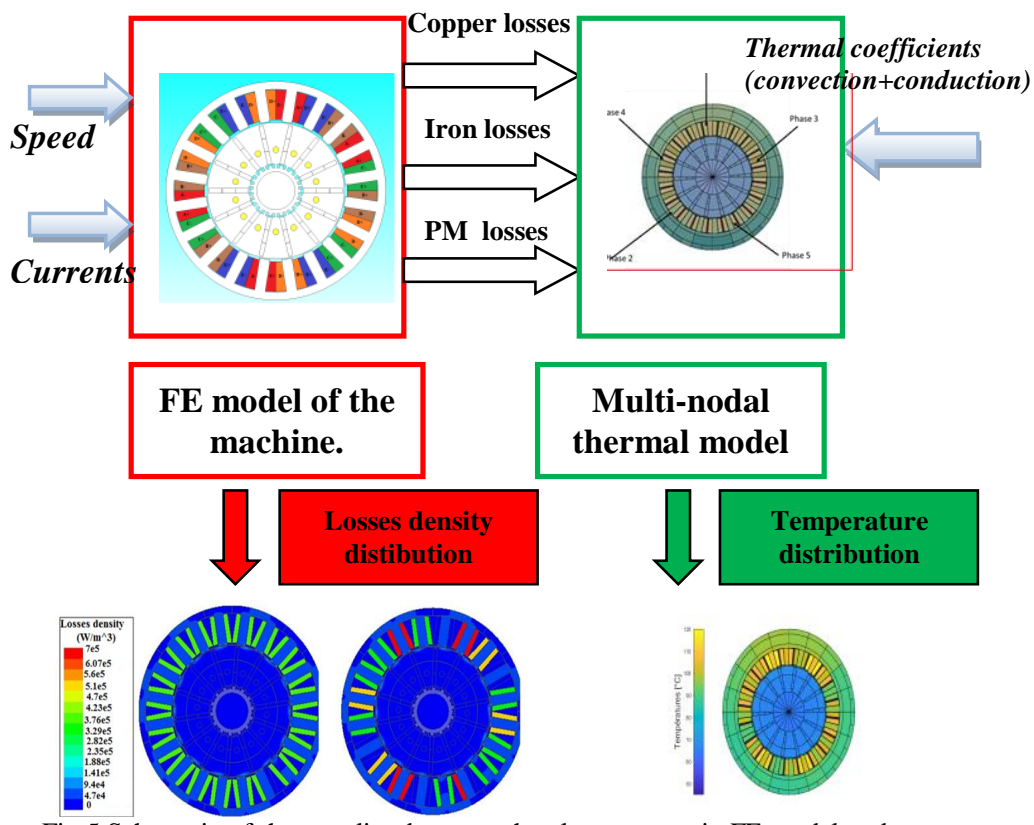

Fig.5.Schematic of the coupling between the electromagnetic FE model and the thermal nodal model.

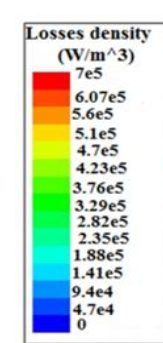

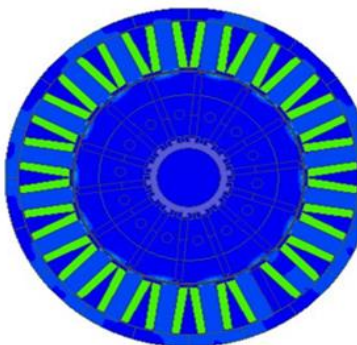

(a)

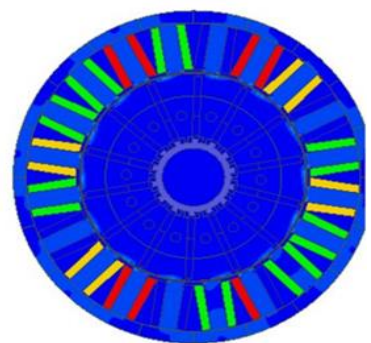

(b)
Fig.6. Losses density distribution calculated by FE in the studied five-phase machine (speed $750 \mathrm{rpm}$ and copper losses of 250W). (a) Healthy mode operation (b) Opened-phase operation mode without reconfiguration of control.

\section{CFD simulation}

CFD calculations are achieved with Fluent 13, with a geometry directly imported from simplified CAD drawings. The Reynolds Averaged Navier-Stokes equations are solved using the $\mathrm{k}-\varepsilon$ realizable model. The boundary conditions imposed on the domain are relatively simple. Only the static 
pressure is imposed constant on the boundaries of the domain. A rotating marker is used to model the rotation of the rotor. The fixed walls therefore have zero absolute velocity while the moving walls have their relative velocity zero.

Simulations show that the air enters through the axial openings of the machine and is rejected by the radial openings (see Figs.1.b, 1.d,. Fig.7 and Fig.8). Finally, two outgoing flows and two incoming flows as well as the flow at the air gap can be defined. In Fig.9. the incoming and outgoing flows deduced from the CFD simulations are summarized and which will be considered in the SAME model.

\section{Thermal BeHAVIOR Of THE MACHINE IN BOTH HEALTHY AND FAULTY OPERATIONS}

\section{A. Healthy operation mode}

The temperature distribution for this mode is calculated under SAME code based on the losses cartography show in Fig.6.a. 151 heat sources are considered in this case. The results are presented for different section of the machine in Fig.10. The critical warmer points are located at the endwindings since the power losses are maximum in this part of windings. The upper part of the machine is warmer by about $32^{\circ} \mathrm{C}$ compared to the lowest winding temperature according to the experimental test results presented in Table. I. This can be explained by the dissymmetry of the machine design. The upper part does not possess cooling fins and the connection box is located at this part of the machine which forms a barrier for the heat exchange.

The simulations are compared with experimental measurements obtained from the resistance thermal detectors. We find a good agreement with acceptable relative error (between $1 \%$ to $18 \%$ according to Table.I.) due probably to an internal dissymmetry in the machine.

\section{B. Faulty operation mode}

In Fig.11, the distribution of the temperatures for different sections obtained by SAME, are presented for the faulty operation mode. The levels of temperature in simulation follow well the levels of the losses that were provided. As example the temperatures are the lowest where the losses are zero (in the opened-phase).

A comparison study between the measured temperatures and the ones obtained by the thermal nodal model is given in Table II for the faulty operation mode (at $750 \mathrm{rpm}$ for 250 $\mathrm{W}$ of copper losses). Here, it should be noticed that the nodal model can be used also to predict the motor thermal behavior for different operating conditions and operation modes.

Fig.12. depicted the errors between the resulting temperature obtained from the multi-nodal simulations and the experimental tests. These errors don't exceed $18 \%$.

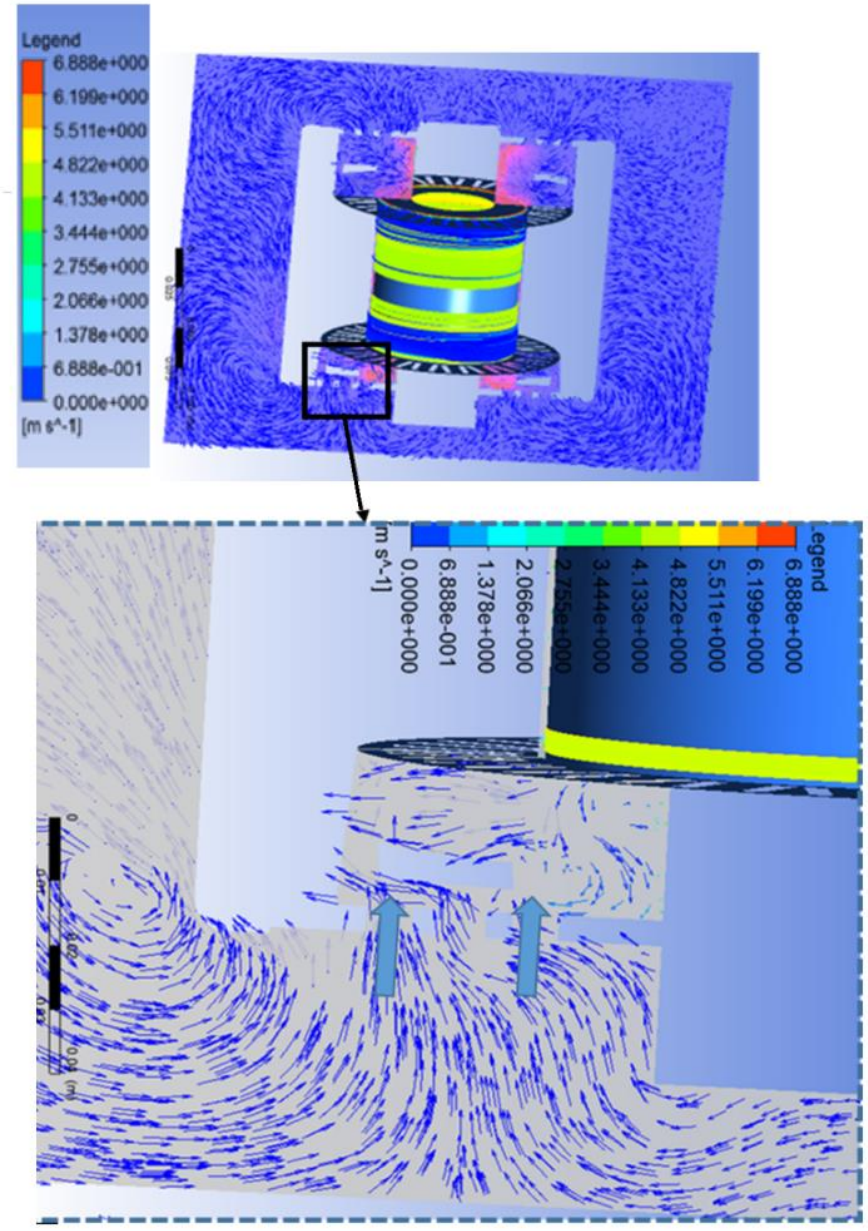

Fig.7. Axial air flow direction for 750rpm.

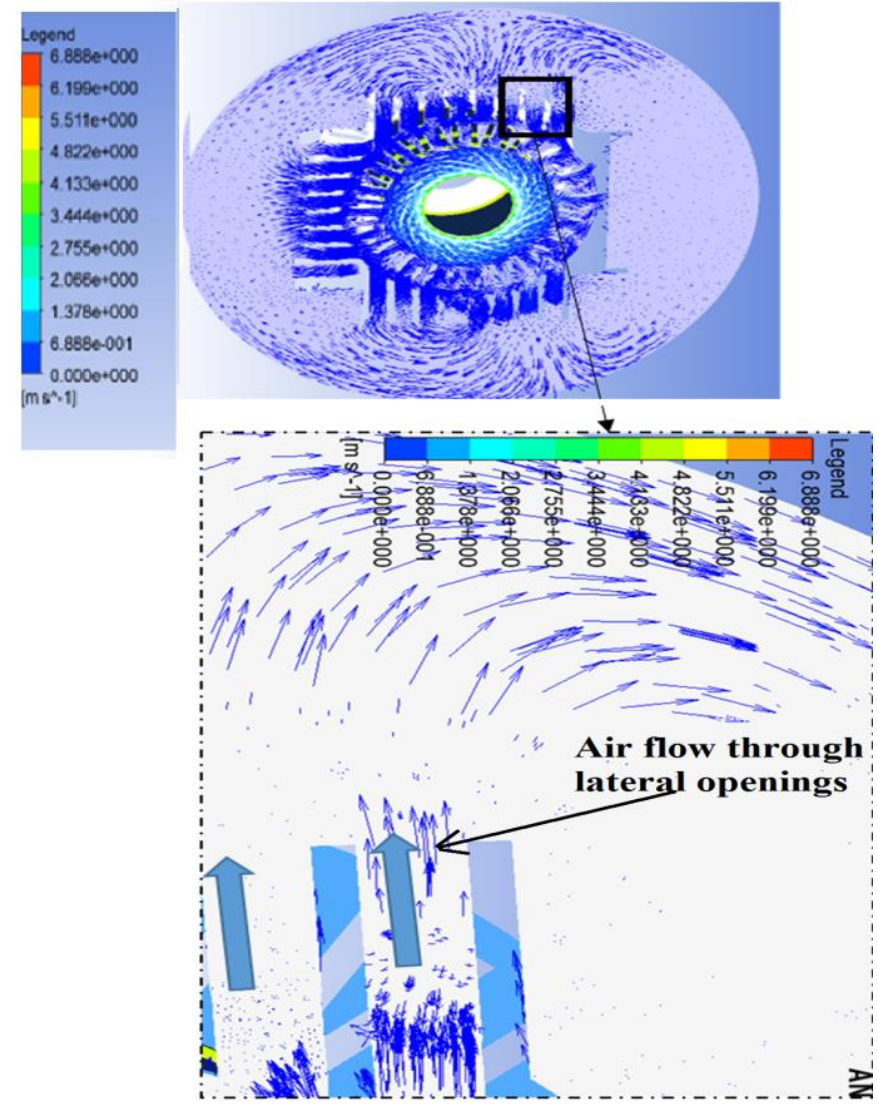

Fig.8. Radial air flow direction for $750 \mathrm{rpm}$ 


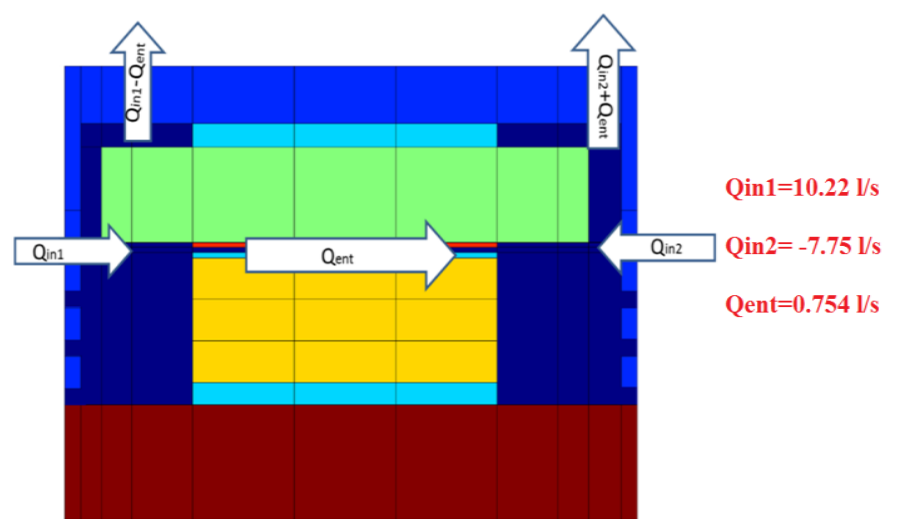

Fig.9. Summarized of different air flow in the machine for healthy mode operation at $750 \mathrm{rpm}$.

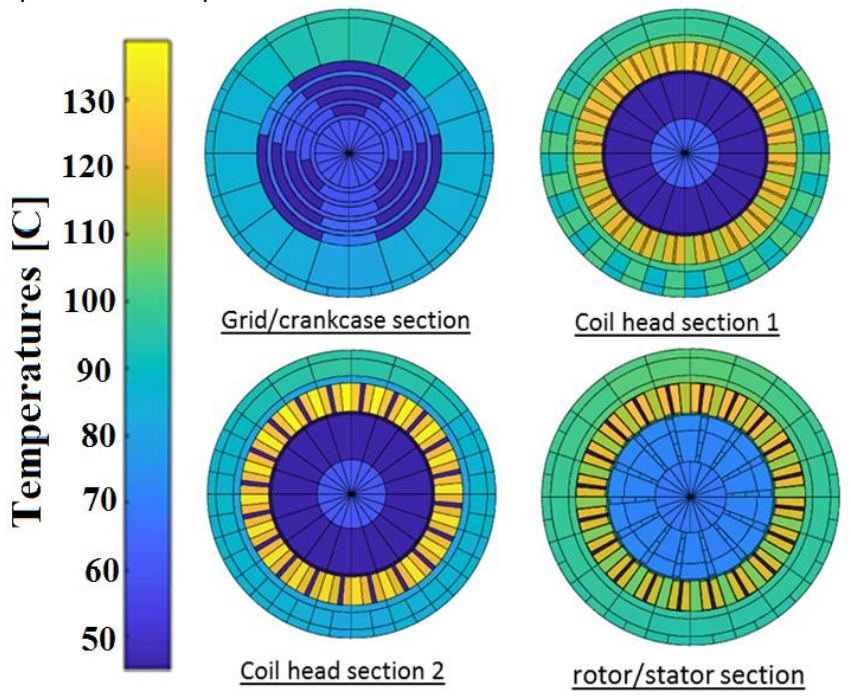

Fig.10. Temperature distribution for different machine sections for healthy mode operation

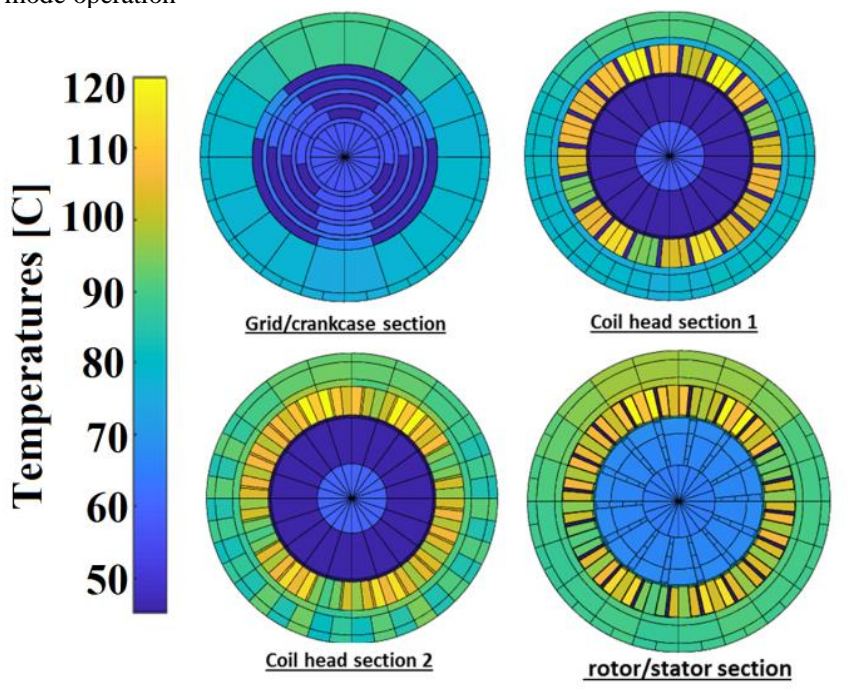

Fig.11. Temperature distribution for different machine sections for faulty mode operation.

\section{CONCLUSION}

A 3D-nodal model with 3050 nodes has been presented for the prediction of the machine temperatures when it is existing an irregular distribution of the losses. The comparison with experimental measurements proves the effectiveness of the nodal modeling. As consequence, it should be possible to use such a modelling in normal and in fault mode in real time in order to adapt the maximum
TABLE I. PREDICTED AND MEASURED TEMPERATURES IN THE MOTOR WINDINGS FOR A HEALTHY MODE (750 RPM, $\left.\mathrm{P}_{\mathrm{J}}=250 \mathrm{~W}\right)$

\begin{tabular}{|c|c|c|c|}
\hline & \multicolumn{3}{|c|}{ Healthy mode } \\
\hline Phase & $\begin{array}{c}\text { Predicted } \\
\text { values ( }\end{array}$ & $\begin{array}{c}\left.{ }^{\circ}\right) \\
\text { Experimental } \\
\text { values }\left({ }^{\circ}\right)\end{array}$ & $\begin{array}{c}\text { Error } \\
\text { percentage } \\
\Delta \boldsymbol{T}(\%)\end{array}$ \\
\hline$a$ & 125.2 & 131 & $4.4 \%$ \\
\hline$b$ & 116.7 & 99 & $17.8 \%$ \\
\hline$c$ & 116.8 & 110.2 & $6 \%$ \\
\hline$d$ & 113.2 & 102 & $11 \%$ \\
\hline$e$ & 114.8 & 114 & $<1 \%$ \\
\hline
\end{tabular}

TABLE II. PREDICTED AND MEASURED TEMPERATURES IN THE MOTOR WINDINGS FOR A FAULTY MODE $\left(750\right.$ RPM, $\left.\mathrm{P}_{\mathrm{J}}=250 \mathrm{~W}\right)$

\begin{tabular}{|c|c|c|c|}
\hline & \multicolumn{3}{|c|}{ Faulty mode } \\
\hline Phase & $\begin{array}{c}\text { Predicted } \\
\text { values }\left({ }^{\circ}\right)\end{array}$ & $\begin{array}{c}\text { Experimental } \\
\text { values }\left({ }^{\circ}\right)\end{array}$ & $\begin{array}{c}\text { Error } \\
\text { percentage } \\
\Delta \boldsymbol{T}(\%)\end{array}$ \\
\hline$a$ & 119,73 & 105,5 & $13.5 \%$ \\
\hline$b$ & 109,35 & 110,2 & $<1 \%$ \\
\hline$c$ & 106,35 & 105,4 & $<1 \%$ \\
\hline$d$ & 108,65 & 108,1 & $<1 \%$ \\
\hline$e$ & 128,01 & 117,4 & $9 \%$ \\
\hline
\end{tabular}

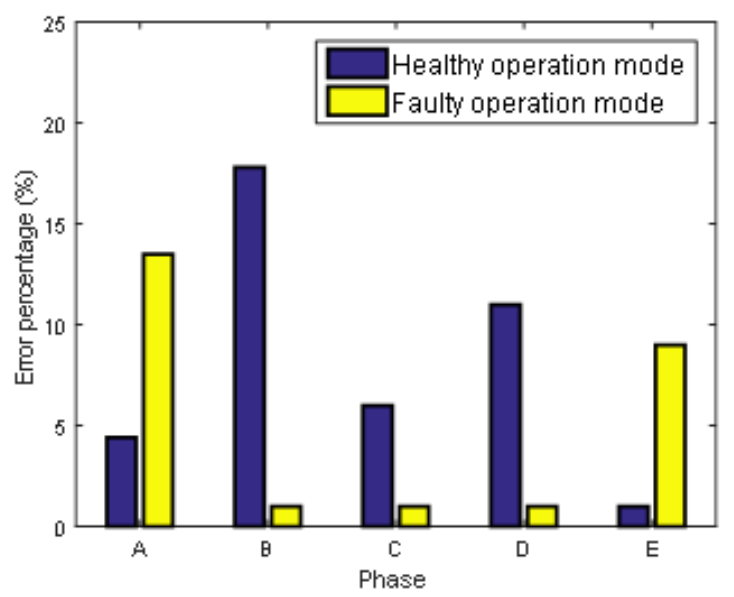

Fig.12.Percentage of error between the obtained temperature resulting form the multi-nodal model and those resulting from the experimental tests.

currents that can be imposed to the machine. Further development intends to adapt automatically the calculation of the level of losses with the temperature in order to prevent thermal runaway in the machine. The general aim is to reduce the thermal margin securities in order to use the electrical machine with its maximum torque capabilities.

\section{ACKNOWLEDGMENT}

This work has been achieved within the framework of CE2I project. CE2I is co-financed by European Union with the financial support of European Regional Development Fund (ERDF), French State and the French Region of Hautsde-France.

\section{REFERENCES}

[1] R. Abebe, G. Vakil, G.L. Calzo, T.Cox, S.Lambert, M. Johnson, C. Gerada and B. Mecrow "Integrated motor drives: state of the art and future trends," in IET Electric Power Applications, vol. 10, no. 8, pp. 757-771, September 2016.

[2] T. M. Jahns and H. Dai, "The past, present, and future of power electronics integration technology in motor drives," in CPSS Trans. 
on Power Electronics and Applications, vol. 2, no. 3, pp. 197-216, September 2017.

[3] D. Richard and Y. Dubel, "Valeo StARS Technology: A Competitive Solution for Hybridization," 2007 Power Conversion Conference Nagoya, Nagoya, 2007, pp. 1601-1605.

[4] Y. Burkhardt, A. Spagnolo, P. Lucas, M. Zavesky and P. Brockerhoff, "Design and analysis of a highly integrated 9-phase drivetrain for EV applications," 2014 International Conference on Electrical Machines (ICEM), Berlin, 2014, pp. 450-456.

[5] A. Schmidhofer, J. Horvat, T. Gabriel, H. Lanzenberger, D. Prix and M. Bichler, "Highly integrated power electronics for a $48 \mathrm{~V}$ hybrid drive application," 2013 15th European Conference on Power Electronics and Applications (EPE), Lille, 2013, pp. 1-7.

[6] N. Bianchi, E. Fornasiero and S. Bolognani, "Thermal Analysis of a Five-Phase Motor Under Faulty Operations," in IEEE Transactions on Industry Applications, vol. 49, no. 4, pp. 1531-1538, July-Aug. 2013.

[7] J. Mayer, D. Huger and D. Gerling, "Enhancing post-fault operation performance of multiphase PMSM-machines using transient thermal modeling and optimization," International Aegean Conference on Electrical Machines and Power Electronics and Electromotion, Joint Conference, Istanbul, 2011, pp. 703-708.

[8] I. Bouzidi, A. Masmoudi and N. Bianchi, "Electromagnetic/Thermal Design Procedure of an Aerospace Electric Propeller," in IEEE
Transactions on Industry Applications, vol. 51, no. 6, pp. 4364-4371, Nov.-Dec. 2015.

[9] T. Jiang, G. Liu and H. Zhou, "Simplified thermal modeling of faulttolerant permanent-magnet motor by using lumped parameter network," 2014 IEEE Conference and Expo Transportation Electrification Asia-Pacific (ITEC Asia-Pacific), Beijing, 2014, pp. 14.

[10] Y. Bertin, E. Videcoq, S. Thieblin and D. Petit, "Thermal behavior of an electrical motor through a reduced model," in IEEE Transactions on Energy Conversion, vol. 15, no. 2, pp. 129-134, June 2000.

[11] A. S. Bornschlegell, J. Pelle, S. Harmand, A. Fasquelle and J. P. Corriou, "Thermal Optimization of a High-Power Salient-Pole Electrical Machine," in IEEE Transactions on Industrial Electronics, vol. 60, no. 5, pp. 1734-1746, May 2013.

[12] Y. K. Chin and D. A. Staton, "Transient thermal analysis using both lumped-circuit approach and finite element method of a permanent magnet traction motor," 2004 IEEE Africon. 7th Africon Conference in Africa (IEEE Cat. No.04CH37590), 2004, pp. 1027-1035 Vol.2.

[13] P.O. Jandaud,"Etude et optimisation aérothermique d'un alternodémarreur" , Ph.D dissertation, University of Valenciennes and Hainaut-Cambresis, France, 2013. 